\title{
Perception is a two-way junction: Feedback semantics in word recognition
}

\author{
DIANE PECHER \\ University of Amsterdam, Amsterdam, The Netherlands
}

\begin{abstract}
Feedback semantics refers to whether a specific meaning can be represented by only one word (consistent) or by several words (inconsistent) - that is, whether a word has synonyms (e.g., jail) or not (e.g., milk). Models of word perception that allow feedback activation from semantics to orthography and phonology predict that performance should be worse for words that are feedback inconsistent (words with a synonym) than for words that are feedback consistent (words without a synonym). The present study showed that both naming and lexical decision responses are faster and more accurate to consistent than to inconsistent words. The results provide support for models that allow feedback activation between phonology, orthography, and semantics.
\end{abstract}

Models of word processing typically identify three types of information that play a role in the recognition of words: orthography (spelling), phonology (sound), and semantics (meaning) (Masson, 1995; Plaut, McClelland, Seidenberg, \& Patterson, 1996; Van Orden \& Goldinger, 1994). These models predict that the consistency of the spelling to sound mapping of a word affects processing of the word. Consistency of spelling to sound mapping refers to the number of different pronunciations that are possible for a certain spelling pattern. A spelling body is consistent if it has only one pronunciation (e.g., _uck: luck, duck, buck). A spelling body is inconsistent if it has several different possible pronunciations (e.g., _eat: great, sweat, beat). Most models predict that inconsistency in the mapping of orthography to phonology will slow down word processing. In these models, a word with an inconsistent spelling may activate several possible pronunciations, which leads to a competition process that has to be resolved before a response (e.g., naming the word) can be given. Several researchers have obtained consistency effects in naming and lexical decision (Andrews, 1982; Glushko, 1979; Stone, Vanhoy, \& Van Orden, 1997; Tarraban \& McClelland, 1987; Ziegler, Montant, \& Jacobs, 1997).

In some models an additional principle is the bidirectional flow of activation between processing units (Van Orden \& Goldinger, 1994). Stone et al. (1997) tested an

Experiment 3 was done while D.P. was a visiting research scholar at the University of California at Riverside on a TALENT stipend from the Netherlands Organization for Scientific Research (NWO). I am grateful to René Zeelenberg, Martin van Leerdam, Eric-Jan Wagenmakers, Guy Van Orden, Johannes Ziegler, Anny Bosman, Annette De Groot, and Michael Masson for helpful suggestions during various stages of this research. I am also grateful to Cheryl Bustamante and Marit Paul for their help with Experiment 3 and to Curt Burgess for allowing me to use his lab facilities. Correspondence should be addressed to D. Pecher, Department of Psychonomics, University of Utrecht, Heidelberglaan 2, 3584 CS Utrecht, The Netherlands (e-mail: d.pecher@fss.uu.nl). interesting prediction of these types of models-namely, that inconsistency of phonology to orthography mappings should interfere with word reading. A pronunciation (e.g., /Yn/) that can be spelled in more than one way (e.g., sign, fine) is feedback inconsistent. Responses were slower and less accurate to feedback-inconsistent words than to feedback consistent words. They called this the inconsistency effect of feedback phonology. Other studies have also shown an effect of feedback phonology in printed word recognition (Ziegler, Montant, \& Jacobs, 1997; but see Peereman, Content, \& Bonin, 1998) and an effect of feedback orthography in spoken word recognition (Ziegler \& Ferrand, 1998). These studies show feedback consistency effects at the orthographic and phonologic levels. However, models of word recognition assume that semantics also play a role in word recognition. Models that incorporate the bidirectional flow of activation therefore predict that feedback semantics also plays a role in word recognition. Thus far this influence of feedback semantics has not been investigated. In the present paper I will therefore investigate the effect of semantic feedback consistency on word reading.

The effect of feedback consistency is an important finding because it places restrictions on models of word recognition. Let us first look at a possible way in which models can explain feedback consistency effects. One important class of models that deal with feedback activation are neural network models. Neural network models of word processing consist of three (or more) families of processing units that deal with orthography, phonology, and semantics. A specific word can be represented by a specific pattern of activation of these units. The interconnectivity of the units allows recovery of the complete pattern from an incomplete pattern. The activation of a unit can be viewed as a value on a dimension, and the possible activations of all units can be viewed as defining a multidimensional space. A pattern associated with a word is a point attractor in this space. Resonance in the system 
leads to movement toward such a point attractor. Presentation of a printed word results in a pattern of activation of the orthographic units. Activation then flows from the orthographic units to the phonologic units and the semantic units. Next, activation flows back to the orthographic units and between the phonologic and semantic units. This dynamic back-and-forth flow of activation continues until the system reaches an attractor state. This type of model, which allows feedback activation, can be contrasted with the type of models that allow only feedforward activation from stimulus to response (Stone et al., 1997).

In both feedback and nonfeedback models, (feedforward) inconsistency in the mappings from the pattern in one group of units to the pattern in another group of units will slow down word processing (i.e., activation works in opposing directions and thus more time is needed to reach an attractor). These models can explain the orthography to phonology inconsistency effect: Initial activation from the orthographic units may activate several patterns in the phonologic units that correspond to the different sounds that are associated with that spelling. Thus, reading a word that has inconsistent spelling should be slower than reading a word with consistent spelling. This prediction is made both by models that assume that activation flows in only one direction (from stimulus to response) and by models that assume that activation flows in all directions. However, the latter type of models also make the prediction that inconsistency from phonology to orthography should hinder reading performance. If a sound (e.g., /et/) can be spelled in several ways (late, wait, great, weight), reading performance is predicted to slow down. The initial activation from the orthographic pattern activates a phonologic pattern, and this pattern in turn activates several orthographic patterns. Because this conflict has to be resolved (the system must reach one attractor state), more processing is needed than if a sound can be spelled only in one way (e.g., /ob/in job). This prediction was confirmed by Stone et al. (1997) and Ziegler, Montant, and Jacobs (1997), who showed that lexical decisions and naming of printed words were harmed by sound to spelling inconsistency, and by Ziegler and Ferrand (1998), who showed that lexical decisions of auditorily presented words were harmed by spelling to sound inconsistency.

These studies show that resonance between orthography and phonology plays a role in word perception. In the present study, I investigate whether resonance between semantics and both orthography and phonology also plays a role in word processing. In alphabetical languages such as English the correlation between orthography and phonology is much higher than the correlations between orthography and semantics and phonology and semantics (Van Orden \& Goldinger, 1994). Moreover, the correlation between phonology and orthography is especially strong at the letter and phoneme level. At this level there is no correlation with the semantic level. Therefore the role of semantics in the initial buildup of activation patterns is expected to be smaller than the role of phonology and orthography. However, several studies have shown that semantics can play a role in word processing, although the effects can sometimes be quite small. For example, it has been observed that lexical decision and naming of words is affected by imageability (De Groot, 1989; Strain, Patterson, \& Seidenberg, 1995), semantic ambiguity (Azuma \& Van Orden, 1997; Borowsky \& Masson, 1996; Jastrzembski, 1981; Kellas, Ferraro, \& Simpson, 1988; Pexman \& Lupker, 1999), and by the presence of semantically related words (McNamara, 1992; Meyer \& Schvaneveldt, 1971; Pecher, Zeelenberg, \& Raaijmakers, 1998; Seidenberg, Waters, Sanders, \& Langer, 1984).

In the present study, semantic feedback consistency was manipulated by using words with or without a familiar synonym. According to dynamic neural network models, a word (e.g., jail) with a familiar synonym ( prison) will activate a pattern in the semantic units (representing the meaning of jail and prison), and feedback from the semantic units will result in the activation of several patterns in the phonologic and orthographic units (e.g., those for jail and prison). Semantic feedback for words without a synonym (e.g., milk) will activate only one pattern in the phonologic and orthographic units. Therefore reaction times (RTs) are predicted to be faster for words without synonyms than for words with synonyms. The effects of semantic variables may be larger for words that have inconsistent mappings between orthography and phonology (Farrar, Van Orden, \& Hamouz, 1998; Strain et al., 1995). This could pose a problem for the present series of experiments. Experiments 1 and 2 were performed with a Dutch subject pool (in fact, the subjects were Dutch-English bilinguals). Because most Dutch words have consistent mappings between orthography and phonology, the effect of semantic variables may be too small to observe. Therefore, in order to try to maximize the effect of semantic feedback inconsistency, English words were used.

\section{EXPERIMENT 1 Naming}

\section{Method}

Subjects. Thirty-three students at the University of Amsterdam participated for course credit. All subject were native speakers of Dutch with good command of English. Dutch students typically have good command of English and use English fairly often (Van Hell, 1998). For example, most of the psychology curriculum consists of books and papers in English.

Materials. Two sets of 75 words each were selected. A complete list of the materials can be found in the Appendix. The first set consisted of words with a familiar synonym. These were selected from synonym norms (Whitten, Suter, \& Frank, 1979; Wilding \& Mohindra, 1983) and from dictionaries. The synonyms of a pair could be translated to the same Dutch word (e.g., pain and ache are both translated as pijn). From each pair the less familiar word (e.g., ache) was chosen as target. ${ }^{1}$ This set was the semantic feedback inconsistent condition. The second set of 75 words consisted of words that did not have a familiar synonym. This set was selected from a larger set of words that were in the same word frequency and length range as the synonym set. This larger set was extracted from the MRC Psycholinguistic Database (Coltheart, 1981). From this larger set all words that had a synonym or a word that was similar in mean- 
ing were eliminated. This was done by looking up the words in thesauri and by checking if the Dutch translation of the word could be translated back to more than one English word. The remaining set was further reduced by finding the subset of 75 words that matched the set of synonyms best on word frequency and length. This set was the semantic feedback consistent condition. All selected words had stress on the first syllable, and the two sets of targets were matched on first letter (with two exceptions: yesterday-usual and key-quest). This was done so that differences in sensitivity of the voice key could not account for differences between the two sets. The mean length in letters was 5.5 for the feedback inconsistent set, and 5.5 for the feedback consistent set. The mean log lemma frequency was 2.82 for the feedback inconsistent set and 2.80 for the feedback consistent set (CELEX English database, 1993). Six words were used for the practice trials. No word appeared more than once during the entire experiment.

Procedure. The words were presented on a PC screen for naming. A trial consisted of a warning signal $(* * * * *)$ that was displayed for $500 \mathrm{msec}$, followed immediately by the target, which remained on the screen until a response was made. Subjects responded by reading the word aloud. RTs were measured with a voice key. The experimenter recorded errors and voice key failures.

\section{Results}

Incorrect responses (mispronunciations) were discarded, as were correct responses with RTs exceeding $1,000 \mathrm{msec}(0.3 \%$ of the data). Voice key errors resulted in loss of $3.7 \%$ of the data. The mean results are presented in Table 1. RTs were slower for the feedback-inconsistent condition than for the feedback-consistentcondition. This difference was significant for subjects $\left[F_{1}(1,32)=9.06\right.$, $p<.01]$, but not for items $\left[F_{2}(1,148)=1.53, p>.10\right]$. If either $F_{1}$ or $F_{2}$ is not significant, then $\min F^{\prime}$ is also not significant (Clark, 1973). More errors were made in the feedback-inconsistent condition than in the feedbackconsistent condition; this difference was significant by subjects $\left[F_{1}(1,32)=14.88, p<.001\right]$, but not by items $\left[F_{2}(1,148)=1.13, p>.10\right]$. Thus, naming responses were slower and less accurate to feedback-inconsistent words than to feedback-consistent words. However, the effect of feedback consistency was quite small and not significant by items. This may have been due to the naming task. Ziegler, Montant, and Jacobs (1997) also observed small effects of phonologic feedback inconsistency in naming. They observed a larger effect in lexical decision. Ziegler,

Table 1

Mean Reaction Times (RTs, in Milliseconds) and Error Rates (ERs) in Percentages for Experiments 1, 2, and 3

\begin{tabular}{|c|c|c|c|c|}
\hline \multirow[b]{2}{*}{ Experiment } & \multicolumn{2}{|c|}{ RT } & \multicolumn{2}{|c|}{ ER } \\
\hline & $M$ & $S E$ & $M$ & $S E$ \\
\hline \multicolumn{5}{|l|}{1 (Naming) } \\
\hline Consistent & 554 & 7.4 & 3.4 & 0.5 \\
\hline Inconsistent & 559 & 7.9 & 5.3 & 0.6 \\
\hline Difference & 5 & & 1.9 & \\
\hline \multicolumn{5}{|l|}{2 (Lexical Decision) } \\
\hline Consistent & 622 & 8.6 & 7.6 & 1.0 \\
\hline Inconsistent & 636 & 7.2 & 9.9 & 1.3 \\
\hline Difference & 14 & & 2.3 & \\
\hline \multicolumn{5}{|l|}{3 (Lexical Decision) } \\
\hline Consistent & 620 & 11.9 & 5.0 & 0.4 \\
\hline Inconsistent & 645 & 11.2 & 6.4 & 0.6 \\
\hline Difference & 25 & & 1.4 & \\
\hline
\end{tabular}

Montant, and Jacobs argued that lexical decision is more sensitive to feedback inconsistency of phonology because the task requires precise knowledge of a words' spelling. However, lexical decision may be more sensitive in general because the task may require more complete recognition of a word than the naming task. Therefore the next experiment was done using a lexical decision task. To increase the power of this experiment, more items were used than in Experiment 1.

\section{EXPERIMENT 2 Lexical Decision}

\section{Method}

Subjects. Fifteen students at the University of Amsterdam participated for course credit. All subjects were native speakers of Dutch with a good command of English. None had participated in Experiment 1.

Materials. Two sets of 127 words each were selected. Each set consisted of the 75 words used in Experiment 1 plus 52 additional words. These additional words were selected in the same way as the first set, except for the stress and first letter restrictions. The two sets were matched on length in letters and word frequency. The mean length in letters was 6.04 for the feedback-inconsistent set, and 6.08 for the feedback-consistent set. The mean log lemma frequency was 2.78 for the feedback-inconsistent set and 2.69 for the feedbackconsistent set (CELEX English database, 1993).

A set of 254 nonwords was created. Sixty-one of the nonwords were pseudohomophones, ${ }^{2}$ either taken from Stone and Van Orden (1993) or created by replacing a part of a word by a different spelling for the same sound (Ziegler, Stone, \& Jacobs, 1997)—for example, replacing the $u r$ in surface with $i r$ to make sirface. The remaining nonwords were created by changing one or two letters of existing English words. None of the nonwords were derived from the critical targets. All nonwords were pronounceable. A further set of 6 nonwords and 6 words was created for the practice trials. No word or nonword appeared more than once during the entire experiment.

Procedure. The words and nonwords were presented on a PC screen for lexical decision. A trial consisted of a warning signal $(* * * * *)$ that was displayed for $500 \mathrm{msec}$, followed immediately by the target, which remained on the screen until a response was made. Subjects responded "word" by pushing a button with their right index finger, and "nonword" by pushing a button with their left index finger. They were instructed to respond as quickly as possible without making errors. If an error was made, the word FOUT (error) was presented for $500 \mathrm{msec}$. If a response exceeded the deadline of 1,500 msec, the word LANGZAAM (slow) was presented for $500 \mathrm{msec}$. After 1,000 msec the next trial started. Stimuli were presented in blocks of 100 trials (except the final block, which had 108 trials). After every block there was a short break, and feedback was given on the percentage of errors. If this percentage exceeded $15 \%$, the subject was urged to respond more accurately. The order of the stimuli was randomized.

\section{Results}

Correct responses with an RT exceeding 1,000 msec were discarded (3.6\% of the data). The mean results are presented in Table 1. RT analyses are based on correct responses only. RTs were slower for the feedbackinconsistent condition than for the feedback-consistent condition. This difference was significant for subjects $\left[F_{1}(1,14)=17.19, p<.01\right]$ and for items $\left[F_{2}(1,252)=\right.$ $\left.5.08, p<.05, \min F^{\prime}(1,164)=3.92, p<.05\right]$. More errors were made in the feedback-inconsistent condition than in 
the feedback-consistent condition; this difference was significant for subjects $\left[F_{1}(1,14)=5.89, p<.05\right]$, but not for items $\left[F_{2}(1,252)=2.33, p>.10\right]$. Thus, lexical decisions were slower and less accurate to feedback-inconsistent words than to feedback-consistent words.

Together with the results of Experiment 1, this is evidence that feedback inconsistency indeed harms performance in word recognition. This has implications for the architecture of word recognition models. However, before this strong conclusion is made, two issues need to be addressed. First, it may be problematic that the effects were found with Dutch subjects. These subjects were performing the task in their second language, and this might have affected their word processing somehow. A stronger claim could be made if the same effect could be found with native English speakers. A second issue is that other confounding variables may have affected processing speed. The sets used in Experiments 1 and 2 were matched on word frequency and length, but not on other variables such as bigram frequency or neighborhood density. In addition, some words were ambiguous, and this may have complicated the synonymy issue. For example, the word key does not have a synonym for its lock meaning, but there are synonyms for other meanings of key, such as lever or button (as in telegraph key or keyboard). Therefore, a second lexical decision experiment was conducted in which the stimulus sets were controlled for more variables and subjects who were native speakers of English were used.

\section{EXPERIMENT 3 Lexical Decision}

\section{Method}

Subjects. Twenty-eight students from the University of California, Riverside, participated for course credit. All subjects were native speakers of English.

Method. A new set of words was selected from the stimuli used in Experiment 2. First, all words that had two or more unrelated meanings according to the Webster's dictionary (1989) were removed. From the remaining set, a few more words were removed so that the consistent and inconsistent sets had the same number of words (65), and the words of the two sets were matched on several word variables. Word frequency was taken from the CELEX database, and a second measure of word frequency was taken from the HAL corpus (Burgess \& Livesay, 1998). This corpus consists of word forms for which frequency counts are taken from Usenet discussion groups. The HAL corpus was also used to calculate bigram frequencies and neighborhood densities with LexStat (Walter van Heuven, www.nici.kun.nl/ heuven/ ). Length in letters, phonemes, and syllables were taken from the MRC database. The measures were 3.4 and 3.3 mean $\log$ HAL frequency, 2.6 and 2.6 mean $\log$ lemma Celex frequency, 757307 and 767860 mean bigram frequency, 3.9 and 3.9 mean neighborhood density, 6.6 and 6.7 mean length in letters, 5.4 and 5.4 mean length in phonemes, and 2.1 and 2.1 mean length in syllables for the consistent and inconsistent sets, respectively. The spelling of the words was adjusted to American standard (e.g., flavour-flavor). The procedure of the experiment was identical to that of Experiment 2.

\section{Results}

Correct responses with RT exceeding 1,000 msec were discarded ( $6.3 \%$ of the data). The mean results are presented in Table 1. RT analyses are based on correct responses only. RTs were slower for the feedbackinconsistent condition than for the feedback-consistent condition. This difference was significant for subjects $\left[F_{1}(1,27)=32.42, p<.01\right]$ and for items $\left[F_{2}(1,128)=\right.$ $\left.7.50, p<.05, \min F^{\prime}(1,155)=6.09, p<.05\right]$. More errors were made in the feedback-inconsistent condition than in the feedback-consistent condition, this difference was significant for subjects $\left[F_{1}(1,27)=5.76, p<.05\right]$, but not for items $\left[F_{2}(1,128)=1.91, p>.10\right]$. Thus, lexical decisions were slower and less accurate to feedbackinconsistent words than to feedback-consistent words.

\section{Discussion}

The results clearly show a disadvantage in word recognition for words that have a synonym. This provides evidence that printed word processing is affected by feedback semantics. The present finding is in line with the studies that have shown that printed word perception is affected by feedback phonology (Stone et al., 1997; Ziegler, Montant, \& Jacobs, 1997; but see Peereman et al., 1998 ) and that auditory word perception is affected by feedback orthography (Ziegler \& Ferrand, 1998). These results provide further support for models that assume some resonance process during which activation flows in both feedforward and feedback directions.

The feedback-consistency effect appears to be stronger in lexical decision than in naming. Feedback-consistency effects were reliable in both the subject and item analyses when the lexical decision task was used (Experiments 2 and 3), but were reliable only in the subject analysis when the naming task was used (Experiment 1). However, this need not be a problem for feedback models of word recognition. In the naming task, a response can be generated as soon as a stable phonological pattern is achieved. Lexical decision may require full setting of the meaning units (Joordens \& Besner, 1994, but see Borowsky \& Masson, 1996). Van Orden and Goldinger (1994) have argued that the consistency at different grain sizes of orthographic and phonologic patterns is greater than that between orthographic and semantic patterns and that between phonologic and semantic patterns. Because of these stronger consistencies, orthographic-phonologic resonances will cohere earlier than orthographic-semantic and phonologic-semantic resonances. Hence, a phonologic response may become available before a stable pattern is reached in the semantic units. Therefore, a larger effect of semantic variables is expected in lexical decision than in naming. In a study that investigated ambiguity effects, Borowsky and Masson (1996) observed that the effect of semantic ambiguity is present in lexical decision but not in naming. Simulation of the data with a distributed memory model (based on Masson's, 1995, model) showed that in order to fit the data for the naming task, the influence of the semantic units had to be reduced, whereas to fit the data for the lexical decision task, the semantic units were more important. This might explain the present findings. However, this argument depends on the assumption that lexical decision requires more acti- 
vation in the semantic units. The question of how naming and lexical decision are best modeled is beyond the scope of the present paper. The important point is that some of the published feedback models predict that lexical decision is more sensitive to semantic variables than to naming.

The difference between naming and lexical decision in the present results does not mean that semantics do not play a role in naming at all. For example Strain et al. (1995) showed that imageability (a semantic variable) can affect naming responses. However, this effect seems to be restricted to exception words. Strain et al. selected their stimuli so that they all had irregular spelling to sound patterns and found the effect, whereas De Groot (1989) did not select her stimuli on regularity and obtained very weak effects of imageability in naming. De Groot did obtain reliable effects in lexical decision. This again shows that lexical decision is influenced more by semantic variables than naming is.

Other studies have investigated consistency effects at the semantic level. However, these studies have shown effects only of feedforward variables, namely an effect of semantic ambiguity on word processing (Borowsky \& Masson, 1996; Jastrzembski, 1981; Joordens \& Besner, 1994; Kellas et al., 1988; Pexman \& Lupker, 1999). In these studies, inconsistent feedforward mapping from orthography to semantics led to faster responses. This seems counterintuitive, because most models would predict that competition between different meaning patterns slows down processing. A possible explanation of the ambiguity advantage is that in connectionist models, the system starts in a random state and moves toward an end state. Processing time reflects the distance between this starting point and the end state. For ambiguous words there are two possible end states in the meaning units. If the system is likely to end in the state that is closest to the starting point, then on average the closest end state of ambiguous words will be closer to the starting point than that of unambiguous words. Thus, the advantage of ambiguous words might be one of proximity (Borowsky \& Masson, 1996; Joordens \& Besner, 1994).

Another explanation for ambiguity effects in terms of feedback mechanisms has been proposed by Pexman and Lupker (1999). They investigated the different results that are usually observed for polysemous words (i.e., words that are ambiguous only at the semantic level, e.g., bank) and homophones (i.e., words that are ambiguous at both semantic and orthographiclevels, e.g., maid-made). They obtained an advantage for polysemous words and a disadvantage for homophones. They suggested that this pattern of results can be explained by assuming that both are affected by feedback at the orthographic level. For polysemous words, the different patterns in the semantic units feed back to the same orthographic pattern, leading to an enhancement of activation. For homophones the phonological pattern leads to inconsistentfeedback to the orthographic units, leading to a disadvantage. They show that when the nonwords used in the lexical decision task are pseudohomophones, and lexical decisions are presumably based more strongly on orthographic information, the two effects are increased.

The feedback explanation for the polysemy effect is related to the explanation for the present results. In the case of polysemous words, the different meanings of an orthographic pattern feed back to the same orthography, thus enhancing performance. In the case of words with strong synonyms, the orthographic pattern activates a semantic pattern, and this semantic pattern feeds back to different orthographic patterns. This inconsistency for words with strong synonyms slows down word processing. The present results provide further evidence that word processing is best explained by feedback models.

\section{REFERENCES}

ANDrews, S. (1982). Phonological recoding: Is the regularity effect consistent? Memory \& Cognition, 10, 565-575.

Azuma, T., \& Van Orden, G. C. (1997). Why SAFE is better than FAST: The relatedness of a word's meanings affects lexical decision times. Journal of Memory \& Language, 36, 484-504.

Borowsky, R., \& MAsson, M. E. J. (1996). Semantic ambiguity effects in word identification. Journal of Experimental Psychology: Learning, Memory, \& Cognition, 22, 63-85.

Burgess, C., \& Livesay, K. (1998). The effect of corpus size in predicting reaction time in a basic word recognition task: Moving on from Kučera and Francis. Behavior Research Methods, Instruments, \& Computers, 30, 272-277.

CELEX English database (Release E25) [On-line]. (1993). Nijmegen: Centre for Lexical Information.

Clark, H. H. (1973). The language-as-fixed-effect fallacy: A critique of language statistics in psychological research. Journal of Verbal Learning \& Verbal Behavior, 12, 335-359.

Coltheart, M. (1981). The MRC Psycholinguistic Database. Quarterly Journal of Experimental Psychology, 33A, 497-505. Available: http://www.psy.uwa.edu.au/MRCDataBase/uwa_mrc.htm

De Groot, A. M. B. (1989). Representational aspects of word imageability and word frequency as assessed through word association. Journal of Experimental Psychology: Learning, Memory, \& Cognition, 15, 824-845.

Farrar, W. T., Van Orden, G. C., \& Hamouz, V. (1998). When sofa primes TOUCH: Interdependence of spelling, phonologyand meaning in "semantically-mediated" priming. Manuscript in preparation.

GLushKo, R. J. (1979). The organization and activation of orthographic knowledge in reading aloud. Journal of Experimental Psychology: Human Perception \& Performance, 5, 674-691.

JAST RZEMBSKI, J. E. (1981). Multiple meanings, number of related meanings, frequency of occurrence, and the lexicon. Cognitive Psychology, 13, 278-305.

Joordens, S., \& BeSner, D. (1994). When banking on meaning is not (yet) money in the bank: Explorations in connectionist modelling. Journal of Experimental Psychology: Learning, Memory, \& Cognition, 20, 1051-1062.

Kellas, G., Ferraro, F. R., \& Simpson, G. B. (1988). Lexical ambiguity and the timecourse of attentional allocation. Journal of Experimental Psychology: Human Perception \& Performance, 14, 601-609.

Masson, M. E. J. (1995). A distributed memory model of semantic priming. Journal of Experimental Psychology: Learning, Memory, \& Cognition, 21, 3-23.

McNamara, T. P. (1992). Theories of priming: I. Associative distance and lag. Journal of Experimental Psychology: Learning, Memory, \& Cognition, 18, 1173-1190.

Meyer, D. E., \& Schvaneveldt, R. W. (1971). Facilitation in recognizing pairs of words: Evidence of a dependence between retrieval operations. Journal of Experimental Psychology, 90, 227-234.

Pecher, D., Zeelenberg, R., \& RaAijmakers, J. G. W. (1998). Does pizza prime coin? Perceptual priming in lexical decision and pronunciation. Journal of Memory \& Language, 38, 401-418. 
Peereman, R., Content, A., \& Bonin, P. (1998). Is perception a twoway street? The case of feedback consistency in visual word recognition. Journal of Memory \& Language, 39, 151-174.

Pexman, P. M., \& Lupker, S. J. (1999). Ambiguity and visual word recognition: Can feedback explain both homophone and polysemy effects? Canadian Journal of Experimental Psychology, 53, 323-334.

Plaut, D. C., McClelland, J. L., Seidenberg, M. S., \& Patterson, K. (1996). Understanding normal and impaired word reading: Computational principles in quasi-regular domains. Psychological Review, 103, 56-115.

Seidenberg, M. S., Waters, G. S., Sanders, M., \& Langer, P. (1984). Pre- and postlexical loci of contextual effects on word recognition. Memory \& Cognition, 12, 315-328.

Stone, G. O., Vanhoy, M., \& Van Orden, G. C. (1997). Perception is a two-way street: Feedforward and feedback phonology in visual word recognition. Journal of Memory \& Language, 36, 337-359.

Stone, G. O., \& VAN Orden, G. C. (1993). Strategic control of processing in word recognition. Journal of Experimental Psychology: Human Perception \& Performance, 19, 744-774.

Strain, E., Patterson, K., \& Seidenberg, M. S. (1995). Semantic effects in single-word naming. Journal of Experimental Psychology: Learning, Memory, \& Cognition, 21, 1140-1154.

Tarraban, R. \& McClelland, J. L. (1987). Conspiracy effects in word pronunciation. Journal of Memory \& Language, 26, 608-631.

VAN HELL, J. G. (1998). Cross-languageprocessing and bilingualmemory organization. Unpublished doctoral dissertation, University of Amsterdam.

Van Orden, G. C., \& Goldinger, S. D. (1994). The interdependence of form and function in cognitive systems explains perception of printed words. Journal of Experimental Psychology: Human Perception \& Performance, 20, 1269-1291.

WEBSTER's ENCYCLOPEDIC UNABRIDGED DICTIONARY OF THE ENGLISH LANGUAGE (1989). New York: Gramercy Books.

Whitten, W. B., Suter, W. N., \& Frank, M. L. (1979). Bidirectional Synonym Ratings of 464 Noun Pairs. Journal of Verbal Learning \& Verbal Behavior, 18, 109-127.

WiLding, J., \& MohindRa, N. (1983). Preferred synonyms for each noun of 279 synonym pairs. British Journal of Psychology, 74, 91-106.

Ziegler, J. C., \& Ferrand, L. (1998). Orthography shapes the perception of speech: The consistency effect in auditory word recognition. Psychonomic Bulletin \& Review, 5, 683-689.

Ziegler, J. C., Montant, M., \& Jacobs, A. M. (1997). The feedback consistency effect in lexical decision and naming. Journal of Memory \& Language, 37, 533-554.

Ziegler, J. C., Stone, G. O., \& Jacobs, A. M. (1997). What is the pronunciation for -ough and the spelling for $/ \mathrm{u} /$ ? A database for computing feedforward and feedback consistency in English. Behavior Research Methods, Instruments, \& Computers, 29, 600-618.

\section{NOTES}

1. According to familiarity ratings that were collected from a different set of students from the same population.

2. Azuma and Van Orden (1997) have shown that the inclusion of pseudohomophones can enhance semantic effects. However, if all nonwords had been pseudohomophones, the lexical decision task might have become too difficult for Dutch subjects. Therefore only a portion of the nonwords were pseudohomophones.

\section{Stimuli Used in Experiments 1, 2, and 3 (Numbers Indicate in Which Experiment a Word Was Used)}

admiration $(2,3)$

adventure $(2,3)$

advertise $(1,2,3)$

air $(1,2)$

allergic $(2,3)$

almond (1, 2, 3)

army $(1,2)$

arrival (2, 3)

art $(1,2)$

bachelor (2)

bakery $(1,2,3)$

barman (2)

beetle (2)

beggar (2)

biology $(2,3)$

birth $(1,2,3)$

bleed (2)

blood $(1,2)$

bottom $(1,2)$

brainstorm $(1,2,3)$

brake (2)

breath $(2,3)$

bridge $(1,2)$

burn (2)

cage $(1,2)$

camel $(1,2)$

candle $(1,2)$

champion $(1,2,3)$

coffin $(1,2)$

collapse (2)

comb $(1,2)$

compare $(2,3)$ complain $(2,3)$

cross $(1,2)$

day $(1,2)$

deaf $(2,3)$

death $(2,3)$

defender $(2,3)$

describe $(2,3)$

digest (2)

dignity (2)

$\operatorname{dog}(1,2)$

dolphin (2)

earring $(1,2)$

egg $(1,2,3)$

exception (2)

exclusion (2)

favour (1, 2, 3)

favourite $(1,2,3)$

fever $(1,2,3)$

fish $(1,2)$

forget $(2,3)$

frog $(1,2)$

future $(1,2,3)$

gamble $(2,3)$

gambler $(2,3)$

gesture (2)

glass $(1,2,3)$

grandchild (2)

grape $(2,3)$

guess $(1,2,3)$

hair $(1,2,3)$

haircut $(2,3)$

homesick $(1,2,3)$

\section{Consistent Words}

horse $(1,2)$

hospitality (2)

impatience $(2,3)$

improvise $(1,2,3)$

inspire (2)

invade $(2,3)$

invest $(2,3)$

joke $(1,2,3)$

key $(1,2)$

kidney $(1,2)$

kiss $(1,2)$

late $(1,2)$

laughter (1, 2, 3)

$\operatorname{liar}(2,3)$

lion $(1,2)$

mattress $(2,3)$

milk $(1,2,3)$

mill (2)

month $(1,2,3)$

moon $(1,2)$

mortality $(2,3)$

moustache (2)

music $(1,2,3)$

neighbour $(1,2,3)$

nose $(1,2)$

nurse (2)

obsession $(2,3)$

oil $(1,2,3)$

poet $(1,2)$

potato $(2,3)$

prejudice $(1,2)$

presence $(1,2,3)$ pride $(1,2)$

read $(1,2,3)$

reality $(2,3)$

rhyme $(1,2)$

rib $(1,2)$

sausage $(1,2)$

scar $(1,2)$

shark $(1,2)$

$\sin (1,2,3)$

skate $(1,2)$

sneeze $(1,2,3)$

spy $(1,2)$

stabilize $(1,2,3)$

strawberry $(1,2,3)$

summer $(1,2)$

survival $(2,3)$

survivor $(2,3)$

swim $(1,2)$

table $(1,2)$

thirst (1, 2, 3)

triangle $(1,2,3)$

truth $(1,2,3)$

voice $(1,2)$

volunteer $(2,3)$

wall $(2,3)$

widow (2)

windmill $(1,2,3)$

wine $(1,2,3)$

wisdom $(1,2,3)$

yellow (2)

yesterday $(1,2,3)$ 


\section{APPENDIX (Continued)}

ache $(1,2,3)$

aid $(1,2)$

astonishment $(2,3)$

author $(1,2)$

autograph $(1,2,3)$

automobile $(1,2)$

barbarian $(2,3)$

battle $(1,2)$

beginning $(2,3)$

belly $(1,2,3)$

bend $(1,2)$

benefit $(1,2,3)$

bug $(1,2)$

bunny $(1,2)$

cab $(1,2)$

cash $(1,2)$

chamber $(1,2)$

coat $(1,2,3)$

command (2)

commerce $(1,2,3)$

conduct (2)

corpse $(1,2,3)$

couple $(1,2)$

dawn $(1,2,3)$

desire (2)

$\operatorname{dish}(1,2)$

earnings $(2,3)$

employment $(2,3)$

engine $(1,2)$

escape (2)

evidence $(1,2,3)$

exam (2) excuse(2)

exhibit (2)

expense $(2,3)$

fabric $(1,2)$

fall $(1,2)$

feeling $(2,3)$

filth $(2,3)$

flavour (2)

fluid $(1,2,3)$

fog $(1,2)$

fool (2)

forecast (1, 2, 3)

forest $(2,3)$

fury $(1,2,3)$

gain $(1,2)$

grease $(1,2,3)$

harm $(1,2)$

hazard $(1,2)$

hopelessness $(1,2,3)$

ill $(1,2)$

infant $(2,3)$

inquiry $(2,3)$

insane $(2,3)$

intention (2)

intersection $(2,3)$

investigation $(2,3)$

jail $(1,2,3)$

joy (2)

kid $(1,2)$

killer $(1,2,3)$

lady $(1,2)$

liberty $(1,2)$
Inconsistent Words

little $(1,2)$

madman $(1,2,3)$

mankind $(1,2)$

mistake (2)

motion $(1,2)$

movie $(1,2,3)$

nakedness $(1,2,3)$

nation $(1,2,3)$

obligation $(2,3)$

odour $(1,2,3)$

outcome $(2,3)$

physician $(2,3)$

picture $(1,2)$

pity $(1,2,3)$

pole (2)

portion $(2,3)$

prey $(1,2,3)$

purchase $(1,2)$

quantity $(2,3)$

quarter (2)

quest $(1,2,3)$

reduction (2)

region $(1,2,3)$

remark (2)

reply (2)

road $(1,2)$

robber $(1,2,3)$

sack $(1,2)$

safety $(1,2,3)$

seat $(2,3)$

shape $(1,2)$

$\operatorname{ship}(1,2)$ shortage $(2,3)$

sickness (2)

sight $(1,2,3)$

silent $(2,3)$

single (2)

smash (2)

soil $(1,2)$

solitude $(2,3)$

sorrow $(2,3)$

source $(1,2)$

speak $(1,2)$

spirit $(1,2)$

store $(1,2)$

strength $(1,2,3)$

$\operatorname{sum}(2,3)$

supper $(2,3)$

tale $(1,2)$

tall (2)

target (2, 3)

terror (2)

threat $(1,2)$

tomb $(1,2,3)$

topic (2)

track (1, 2, 3)

tremble $(2,3)$

trouble $(2,3)$

usual $(1,2)$

village $(1,2,3)$

wages $(1,2,3)$

wedding $(1,2,3)$

weep $(1,2,3)$ 